\title{
Efeito da sacarose e do sorbitol na conservação in vitro de segmentos nodais de mangabeira ${ }^{1}$
}

\author{
Effect of sucrose and sorbitol in the in vitro conservation of mangaba tree nodal \\ segments
}

\author{
Micaele da Costa Santos ${ }^{2}$, Ana da Silva Lédo ${ }^{3 *}$, Carlos Alberto da Silva Lédo ${ }^{4}$, Fernanda Vidigal Duarte Souza ${ }^{4}$ \\ e Josué Francisco da Silva Junior ${ }^{3}$
}

\begin{abstract}
Resumo - A mangabeira (Hancornia speciosa Gomes) é uma espécie cujas regiões de ocorrência natural vêm sofrendo grande pressão antrópica, a qual está provocando erosão genética em muitas populações nativas, principalmente da região Nordeste. Em virtude da existência de poucas coleções de mangabeira conservadas ex situ, evidencia-se a importância do desenvolvimento de um método alternativo e complementar para a conservação de germoplasma dessa espécie. Este trabalho teve como objetivo o aprimoramento técnico-científico da conservação in vitro por crescimento lento de mangabeira. Para avaliar o efeito da sacarose e sorbitol segmentos nodais foram inoculados em tubos de ensaio com $25 \mathrm{~mL}$ de meio de cultura MS suplementado com $1 \mathrm{mg} \mathrm{L}^{-1}$ de ácido indolacético e $1 \mathrm{mg} \mathrm{L}^{-1}$ de benzilaminopurina e diferentes concentrações de sorbitol $\left(10 ; 20 \mathrm{e}^{2} 0 \mathrm{~g} \mathrm{~L}^{-1}\right)$, combinadas com 0 e $15 \mathrm{~g} \mathrm{~L}^{-1}$ de sacarose. Na etapa de recuperação do crescimento, explantes conservados in vitro por 120 dias no experimento anterior foram inoculados em meio de cultura MS sendo a viabilidade das culturas avaliadas aos 30 e 60 dias. A conservação in vitro de segmentos nodais de mangabeira na ausência de sacarose e na presença de 10 ou $20 \mathrm{~g} \mathrm{~L}^{-1}$ de sorbitol é viável sob condições de crescimento lento por 120 dias. Explantes mantidos na ausência de sacarose ou na presença de $10 \mathrm{~g} \mathrm{~L}^{-1}$ de sorbitol na fase de conservação apresentam maior viabilidade na retomada do crescimento até os 60 dias de cultivo.
\end{abstract}

Palavras chave - Hancornia speciosa Gomes. Crescimento lento. Reguladores osmóticos.

\begin{abstract}
The mangaba tree (Hancornia speciosa Gomes) is a specie whose natural occurrence has suffered great human pressure and this is causing genetic erosion in many populations like in the Northeast Brazil. The use of techniques of plant tissue culture for conservation of plant genetic resources presents several advantages over germplasm conservation in the field decreasing cost for the maintenance of collections and decreasing sanitary risk and weather problems. The development of methods conservation of genetic resources still available it is essential. This work aimed at improving technical and scientific in vitro conservation by slow growth of mangaba tree. To evaluate the effect of sucrose and sorbitol nodal segments were inoculated in test tubes with $25 \mathrm{~mL}$ of MS medium supplemented with $1 \mathrm{mg} \mathrm{L}^{-1}$ of indol acetic acid and $1 \mathrm{mg} \mathrm{L}^{-1}$ of benzylaminopurine and different sorbitol concentrations $\left(10 ; 20\right.$ and $\left.40 \mathrm{~g} \mathrm{~L}^{-1}\right)$. They were combined with 0 and $15 \mathrm{~g} \mathrm{~L}^{-1}$ of sucrose. In the recovery stage of the growth explants conserved in vitro for 120 days, in the previous experiment were inoculated on MS medium and the viability of crops evaluated at 30 and 60 days. It is feasible to maintain nodal segments in the absence of sucrose in the presence of 10 or $20 \mathrm{~g} \mathrm{~L}^{-1}$ of sorbitol tree. Explants maintained in the presence of $10 \mathrm{~g} \mathrm{~L}^{-1}$ of sorbitol and in the sucrose absence at conservation phase present higher viability in the growth recovery.
\end{abstract}

Key words - Hancornia speciosa Gomes. Slow-growth. Osmotic regulators.

\footnotetext{
* Autor para correspondência

${ }^{1}$ Recebido para publicação em 17/06/2010; aprovado em 11/04/2011

Parte da Dissertação de Mestrado da primeira autora apresentada ao Programa de Mestrado em Biotecnologia da Universidade Federal de Sergipe ${ }^{2}$ Programa de Pós-Graduação em Biotecnologia/UFS; São Cristóvão-SE, Brasil; micacostal@hotmail.com

${ }^{3}$ Embrapa Tabuleiros Costeiros, Avenida Beira Mar, 3250, Aracaju-SE, Brasil, 49.025-040, analedo@cpatc.embrapa.br, josue@cpatc.embrapa.br

${ }^{4}$ Embrapa Mandioca e Fruticultura, Rua da Embrapa, Cruz das Almas-BA, Brasil, ledo@cnpmf.embrapa.br, fernanda@cnpmf.embrapa.br
} 


\section{Introdução}

A mangabeira (Hancornia speciosa Gomes) é uma frutífera tropical encontrada vegetando, espontaneamente em várias regiões do país, desde o cerrado da região Centro-Oeste até as regiões Norte e Sudeste. Apresenta boa digestibilidade e valor nutritivo, sendo largamente utilizada no comércio de polpas congeladas para produção de sucos, sorvetes, doces, geléias, além da fabricação de vinhos, licores e vinagres (NAIRAN et al., 2006). Está entre as dez espécies selecionadas como de altíssima prioridade de conservação pelo programa Plantas do Futuro do CNPq/Banco Mundial/Global Environment Facility /Ministério do Meio Ambiente (MMA)/Probio coordenado pelo MMA, com maior potencial de uso imediato entre as fruteiras nativas da região Nordeste (FERREIRA et al., 2005).

A cultura de tecidos surge como uma das técnicas biotecnológicas de maior êxito, visto que esta envolve um grupo heterogêneo de técnicas que abrange métodos de propagação e conservação de germoplasma. A manutenção de coleções in vitro tem sido considerada como um método alternativo à conservação de germoplasma, especialmente para espécies propagadas vegetativamente e para espécies que não podem ter suas sementes conservadas a baixa temperatura e umidade, como as da mangabeira.

A conservação de plantas in vitro se baseia no cultivo das coleções em laboratórios, a partir da técnica de cultura de tecidos, permitindo a rápida multiplicação e armazenamento de germoplasma de plantas em ambiente asséptico, livre de patógenos, além da criopreservação com a manutenção de explantes a -196 ${ }^{\circ} \mathrm{C}$ em nitrogênio líquido. Nas condições de crescimento lento, a conservação de germoplasma in vitro pode ser feita a partir de mudanças no ambiente de cultivo para desacelerar ou suprimir totalmente o crescimento das células, tecidos e órgãos (WITHERS; WILLIAMS, 1998). O objetivo de desacelerar o crescimento é aumentar o máximo o intervalo entre os subcultivos, ou estendê-los indefinidamente e diversas técnicas têm sido aplicadas em diferentes espécies alcançando bons resultados (AMARAL, 2005; DIVAKARAN et al., 2006; FORTES; PEREIRA, 2001; HAO; DENG, 2003; ISLAM et al., 2003; KOVALCHUK et al., 2009; LÉDO et al., 2007; LEMOS et al., 2002; SARWAR; SIDDIQUI, 2004; TAHTAMOUNI et al., 2001).

Este trabalho teve como objetivo o aprimoramento do conhecimento técnico-científico para a conservação in vitro de mangabeira das áreas litorâneas do estado de Sergipe, bem como avaliar o desempenho das culturas na etapa de retomada do crescimento.

\section{Material e métodos}

\section{Efeito da sacarose e do sorbitol na conservação in vitro de segmentos nodais de mangabeira}

Os trabalhos foram desenvolvidos no Laboratório de Cultura de Tecidos de Plantas da Embrapa Tabuleiros Costeiros, em Aracaju, SE. Foram utilizados segmentos nodais obtidos de plântulas germinadas in vitro de acessos oriundos da população nativa de mangabeira do Campo Experimental de Itaporanga, SE da Embrapa Tabuleiros Costeiros.

Os segmentos nodais foram inoculados em tubos de ensaio (35 x $127 \mathrm{~mm}$ ) com tampa plástica contendo $25 \mathrm{~mL}$ de meio de cultura de Murashige \& Skoog - MS (MURASHIGE; SKOOG, 1962), suplementado com $1 \mathrm{mg} \mathrm{L}^{-1}$ de ácido indol acético (AIA) e $1 \mathrm{mg} \mathrm{L}^{-1} \mathrm{de}$ benzilaminopurina (BAP) e gelificado com $3 \mathrm{~g} \mathrm{~L}^{-1} \mathrm{de}$ Phytagel $\AA$.

Foram avaliadas diferentes concentrações de sorbitol $\left(10 ; 20\right.$ e $\left.40 \mathrm{~g} \mathrm{~L}^{-1}\right)$, combinadas com 0 e $15 \mathrm{~g} \mathrm{~L}^{-1}$ de sacarose, mais uma testemunha adicional composta de meio de multiplicação (meio MS com $30 \mathrm{~g} \mathrm{~L}^{-1}$ de sacarose, $1 \mathrm{mg} \mathrm{L}^{-1}$ de AIA e $1 \mathrm{mg} \mathrm{L}^{-1}$ de BAP e gelificado com $3 \mathrm{~g} \mathrm{~L}^{-1}$ de Phytagel $($ ). O delineamento experimental utilizado foi o inteiramente casualizado (DIC) em esquema fatorial $2 \times 3+1$ (duas concentrações de sacarose, três concentrações de sorbitol, mais uma testemunha), totalizando sete tratamentos com 20 repetições, sendo cada repetição constituída por um tubo de ensaio com um explante.

Os meios de cultura tiveram o $\mathrm{pH}$ ajustado em torno de 5,8 e foram esterilizados em autoclave a $121{ }^{\circ} \mathrm{C}$, sob pressão $1,05 \mathrm{~kg} \mathrm{~cm}^{-2}$ por 15 minutos. Todos os experimentos foram mantidos em sala de crescimento sob condições de fotoperíodo de 12 horas $\left(52 \mu \mathrm{mol} \mathrm{m} \mathrm{m}^{-2} \mathrm{~s}^{-1}\right.$ de irradiância) e temperatura de $27 \pm 1^{\circ} \mathrm{C}$.

As avaliações foram realizadas aos 30;60; 90 e 120 dias após a inoculação, analisando os seguintes parâmetros: número de brotações adventícias por segmento nodal; número de segmentos nodais por brotação adventícia e porcentagem de abscisão foliar (calculada em função da diferença entre número total de folhas e número de folhas caídas).

Como foram realizadas avaliações sucessivas em diferentes tempos de cultivo in vitro, para a análise de variância foi considerado o DIC em parcela subdividida no tempo, sendo o fatorial nas parcelas e os tempos de cultivo in vitro e suas respectivas interações nas subparcelas.

As médias dos fatores estudados foram comparadas pelo teste de Tukey a 5\% de significância. Para as interações 
significativas dos fatores estudados com o tempo de cultivo in vitro foram ajustadas equações de regressão polinomial. Foi utilizado o programa estatístico SAS.

\section{Retomada do crescimento de explantes provenientes de meio de conservação com sorbitol e sacarose}

Segmentos nodais com brotações adventícias de mangabeira conservados in vitro por 120 dias, em meio de cultura MS com diferentes combinações de sorbitol (10; 20 e $\left.40 \mathrm{~g} \mathrm{~L}^{-1}\right)$ e sacarose $\left(0\right.$ e $\left.15 \mathrm{~g} \mathrm{~L}^{-1}\right)$ foram transferidos para o meio de crescimento.

Os explantes foram inoculados em frascos com capacidade máxima de $250 \mathrm{~mL}$ com tampa plástica contendo $30 \mathrm{~mL}$ de meio de cultura $\mathrm{MS}$, suplementado com $1 \mathrm{mg} \mathrm{L}^{-1}$ de AIA, $1 \mathrm{mg} \mathrm{L}^{-1}$ de BAP e $30 \mathrm{~g} \mathrm{~L}^{-1}$ de sacarose e gelificado com $3 \mathrm{~g} \mathrm{~L}^{-1}$ de Phytagel ${ }^{\circledR}$. $\mathrm{O}$ delineamento experimental foi inteiramente casualizado em esquema fatorial $3 \times 2$ (três concentrações de sorbitol x duas sacarose, utilizadas na etapa de conservação), totalizando seis tratamentos com 20 repetições, sendo a parcela experimental composta por um explante por frasco.

As avaliações foram realizadas aos 0; 30 e 60 após a inoculação atribuindo uma escala de notas adaptada de Lemos et al. (2002) para a viabilidade das culturas, onde as notas correspondem a: 5 - folhas e brotos totalmente verdes; 4 - início do secamento e morte das folhas; 3 secamento e morte das folhas e dos brotos entre 30 e $50 \%$; 2 - mais de $50 \%$ de secamento e morte de folhas e brotos e 1 - folhas e brotos totalmente mortos.

Como foram realizadas avaliações sucessivas em diferentes tempos de cultivo in vitro, para a análise de variância foi considerado o DIC em parcela subdividida no tempo, sendo o fatorial nas parcelas e os tempos de cultivo in vitro e suas respectivas interações nas subparcelas. O programa estatístico utilizado foi o SISVAR e as médias foram comparadas pelo teste de Tukey a 5\% de significância.

\section{Resultados e discussão}

\section{Efeito da sacarose e do sorbitol na conservação in vitro de segmentos nodais de mangabeira}

As interações sacarose $x$ sorbitol e fatorial $x$ testemunha adicional foram significativas para o número de brotos por segmento nodal, número de nós por brotação adventícia e percentagem de abscisão foliar (TAB. 1). Na ausência de sacarose e presença de $10 \mathrm{~g} \mathrm{~L}^{-1}$ de sorbitol foi observado menor crescimento in vitro dos explantes com produção de 1,92 brotações adventícias por segmento nodal e menor porcentagem de abscisão foliar $(1,20 \%)$. A presença de sacarose induziu maior formação de nós por brotação adventícia com $10(6,90)$ e $20 \mathrm{~g} \mathrm{~L}^{-1}$ de sorbitol $(5,92)$ quando comparado aos tratamentos com as mesmas concentrações de sorbitol na ausência de sacarose.

A adição de $15 \mathrm{~g} \mathrm{~L}^{-1}$ de sacarose combinada com as diferentes concentrações de sorbitol promoveu as maiores porcentagens de abscisão foliar. Este resultado pode ser explicado pelo maior metabolismo apresentado pelas culturas mantidas em meio de cultura com sacarose disponível como fonte de carbono e, consequentemente, maior acúmulo de etileno.

Tabela 1 - Médias do número de brotações por segmento nodal (NBS), número de nós por brotação adventícia (NNB) e porcentagem de abscisão foliar (PAF) de explantes de mangabeira em função da concentração de sorbitol e de sacarose

\begin{tabular}{|c|c|c|}
\hline \multirow{2}{*}{ Sorbitol $\left(\mathrm{g} \mathrm{L}^{-1}\right)$} & \multicolumn{2}{|c|}{ Sacarose $\left(\mathrm{g} \mathrm{L}^{-1}\right)$} \\
\hline & 0 & 15 \\
\hline & \multicolumn{2}{|c|}{ NBS } \\
\hline 10 & $1,92 \mathrm{aB}$ & $3,20 \mathrm{aA}$ \\
\hline 20 & $1,84 \mathrm{aA}$ & $1,88 \mathrm{bA}$ \\
\hline 40 & $1,64 \mathrm{aA}$ & $1,65 \mathrm{bA}$ \\
\hline \multirow[t]{2}{*}{ Testemunha } & 2,35 & \\
\hline & \multicolumn{2}{|c|}{ NNB } \\
\hline 10 & $3,92 \mathrm{aB}$ & $6,90 \mathrm{aA}$ \\
\hline 20 & $4,85 \mathrm{aB}$ & $5,92 \mathrm{aA}$ \\
\hline 40 & $3,99 \mathrm{aA}$ & $3,32 \mathrm{bA}$ \\
\hline \multirow[t]{2}{*}{ Testemunha } & 7,03 & \\
\hline & \multicolumn{2}{|c|}{ PAF $(\%)$} \\
\hline 10 & $1,20 \mathrm{cB}$ & $5,71 \mathrm{cA}$ \\
\hline 20 & $4,72 \mathrm{bB}$ & $17,78 \mathrm{abA}$ \\
\hline 40 & $8,62 \mathrm{aB}$ & $11,51 \mathrm{bA}$ \\
\hline Testemunha & 9,84 & \\
\hline
\end{tabular}

Médias seguidas pela mesma letra maiúscula nas linhas e minúscula nas colunas não diferem estatisticamente entre si pelo teste de Tukey a $5 \%$ de significância

A combinação de menor concentração de sacarose $\left(10 \mathrm{~g} \mathrm{~L}^{-1}\right)$ com temperatura de incubação de $18{ }^{\circ} \mathrm{C} \mathrm{em}$ diferentes cultivares de amarílis (Hippeastrum Herb.) mantidas em meio de cultura MS $1 / 2$ foi mais efetiva na conservação in vitro das cultivares, as quais se mantiveram viáveis por 90 dias sem a necessidade de subcultivos (AMARAL, 2005). 
Respostas semelhantes foram obtidas com Passiflora giberti N. E. Brown, Faria et al. (2006) observaram maior crescimento in vitro na presença de sacarose e sorbitol. A sacarose no meio promove um maior desenvolvimento in vitro, já que este é uma fonte de carbono prontamente disponível.

Todas as combinações de sacarose e sorbitol diferiram estatisticamente da testemunha adicional quanto ao número de brotações por segmento nodal e número de nós por brotação adventícia, com exceção da combinação $15 \mathrm{~g} \mathrm{~L}^{-1}$ de sacarose e $10 \mathrm{~g} \mathrm{~L}^{-1}$ de sorbitol para NBS (T2). Para a porcentagem de abscisão foliar as combinações 0 e $15 \mathrm{~g} \mathrm{~L}^{-1}$ de sacarose e $40 \mathrm{~g} \mathrm{~L}^{-1}$ de sorbitol (T5 e T6, respectivamente) não diferiram da testemunha (FIG. 1).

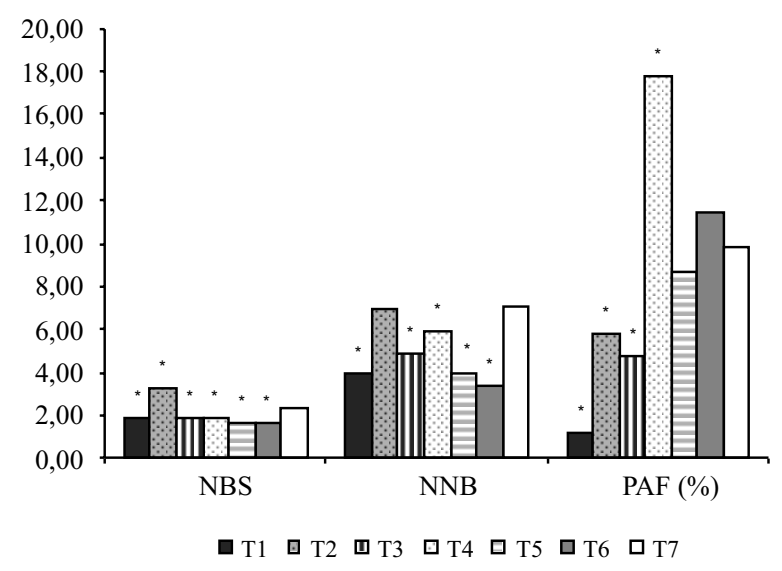

T1 - 0 sacarose +10 sorbitol $\left(\mathrm{g} \mathrm{L}^{-1}\right) ; \mathrm{T} 2-15$ sacarose +10 sorbitol $\left(\mathrm{g} \mathrm{L}^{-1}\right)$; T3- 0 sacarose +20 sorbitol $\left(\mathrm{g} \mathrm{L}^{-1}\right)$; T4- 15 sacarose +20 sorbitol $\left(\mathrm{g} \mathrm{L}^{-1}\right)$; T5- 0 sacarose +40 sorbitol $\left(\mathrm{g} \mathrm{L}^{-1}\right)$; T6- 15 sacarose + 40 sorbitol $\left(\mathrm{g} \mathrm{L}^{-1}\right)$ e T7- MS Padrão $30 \mathrm{~g} \mathrm{~L}^{-1}$ sacarose

Figura 1 - Médias do número de brotações por segmento nodal (NBS), número de nós por brotação adventícia (NNB) e porcentagem de abscisão foliar (PAF) dos tratamentos do fatorial sacarose $\mathrm{x}$ sorbitol com a testemunha adicional MS Padrão. Médias com asterisco diferem da testemunha (Dunnett, $\mathrm{P}=0,05$ )

A interação dos fatores sorbitol $\mathrm{x}$ tempo de cultivo in vitro foi significativa para todas as variáveis avaliadas. A interação sacarose $\mathrm{x}$ tempo de cultivo in vitro foi significativa para o NBS e PAF.

O valor da NBS variou segundo uma regressão linear com acréscimo em função do aumento do tempo de cultivo in vitro nas concentrações de 0 e $15 \mathrm{~g} \mathrm{~L}^{-1}$ de sacarose, indicando que as concentrações testadas não inibiram a formação de brotações adventícias (FIG. 2).
Entretanto, na concentração de $20 \mathrm{~g} \mathrm{~L}^{-1}$ de sorbitol foi observada uma desaceleração no crescimento. Na concentração de $40 \mathrm{~g} \mathrm{~L}^{-1}$ obteve-se uma regressão linear negativa, provavelmente, devido ao efeito tóxico da alta concentração de sorbitol (FIG. 3).

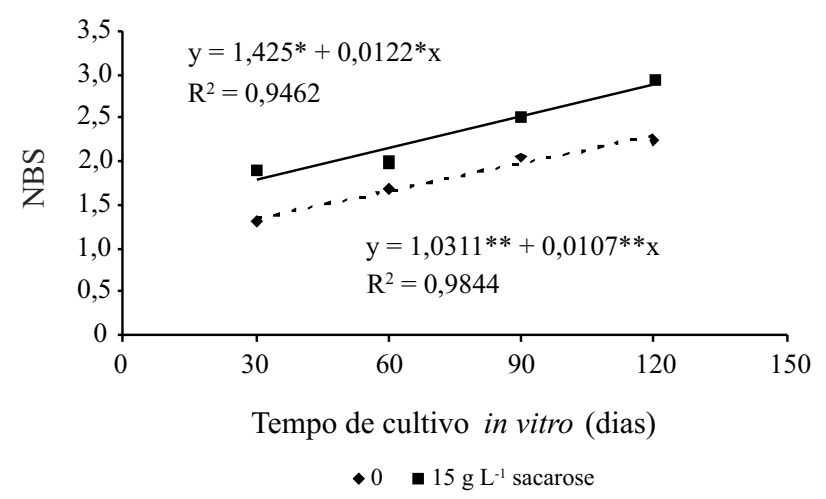

Figura 2 - Número de brotações por segmento nodal (NBS) em função do tempo de cultivo in vitro e da concentração de sacarose

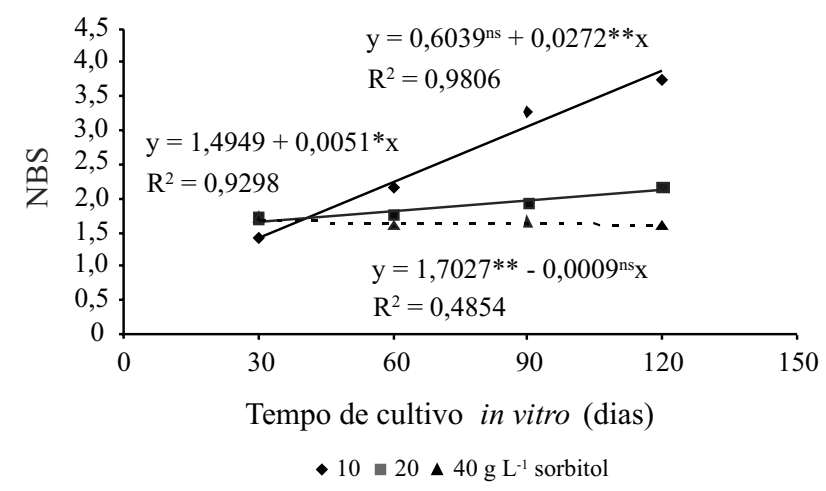

Figura 3 - Número de brotações por segmento nodal (NBS) em função do tempo de cultivo in vitro e da concentração de sorbitol

$\mathrm{O}$ valor da NBS na concentração de $10 \mathrm{~g} \mathrm{~L}^{-1}$ de sorbitol variou segundo uma regressão linear com acréscimo em função do aumento do tempo de cultivo in vitro. Entretanto, nas concentrações de 20 e $40 \mathrm{~g} \mathrm{~L}^{-1}$ de sorbitol foi observada uma regressão quadrática negativa (FIG. 4). O valor máximo de número de nós encontrado, por meio da derivada da equação, para $20 \mathrm{e} 40 \mathrm{~g} \mathrm{~L}^{-1}$ de sorbitol foi de 6,96 e 4,11 aos 118,6 e 91,5 dias de tempo de cultivo, respectivamente. Esses dados demonstram 
que maiores concentrações de sorbitol $\left(20\right.$ e $\left.40 \mathrm{~g} \mathrm{~L}^{-1}\right)$ promoveram um menor crescimento em número de nós. Shibli et al. (1999) relatam que o aumento das concentrações de sacarose (ao contrário do presente trabalho), sorbitol ou manitol reduziram significativamente o crescimento de microbrotos de amêndoa amarga (Amygdalus communis L.), podendo estender o tempo de subcultivo para quatro meses. Renau-Morata et al. (2006) observaram que a adição de $6 \%$ de manitol em meio de cultura afetou negativamente a sobrevivência e multiplicação de culturas de Cedrus atlantica e Cedrus liban. Divakaran et al. (2006) obtiveram êxito na conservação por 360 dias de Vanilla sp. com a redução da sacarose e na presença de 10 ou $15 \mathrm{~g} \mathrm{~L}^{-1}$ de manitol.

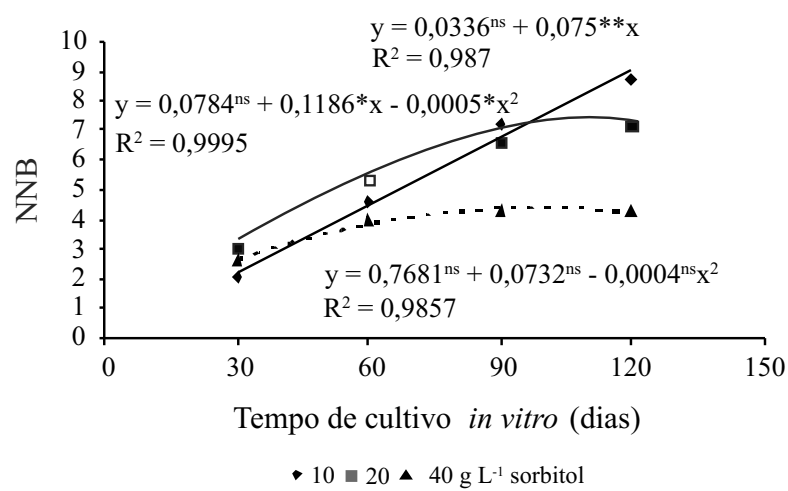

Figura 4 - Número de nós por brotação adventícia (NNB) em função do tempo de cultivo in vitro e da concentração de sorbitol

Efeitos tóxicos devido a altas concentrações de reguladores osmóticos foram relatados por Lédo et al. (2007) e Sá et al.(2011) em coqueiro e mangabeira, respectivamente. O sorbitol é um açúcar álcool que geralmente não é metabolizado pelas plantas e sua ação está relacionada com a modificação do potencial osmótico do meio, removendo o excesso de água intracelular, por gradiente osmótico e assim desacelerando o crescimento vegetal, mas dependendo da concentração ou da espécie em estudo o sorbitol pode ter efeito nocivo (SHIBLI et al., 2006), como o que foi observado neste trabalho na concentração de $40 \mathrm{~g} \mathrm{~L}^{-1}$ de sorbitol.

A porcentagem de abscisão foliar apresentou um comportamento quadrático em relação ao tempo de cultivo in vitro nas concentrações de 0 e $15 \mathrm{~g} \mathrm{~L}^{-1}$ de sacarose, sendo observada maior abscisão foliar em presença da sacarose, devido possivelmente a disponibilização no meio de cultura de fonte de carbono, aumentando o metabolismo in vitro e o acúmulo de etileno (FIG. 5).

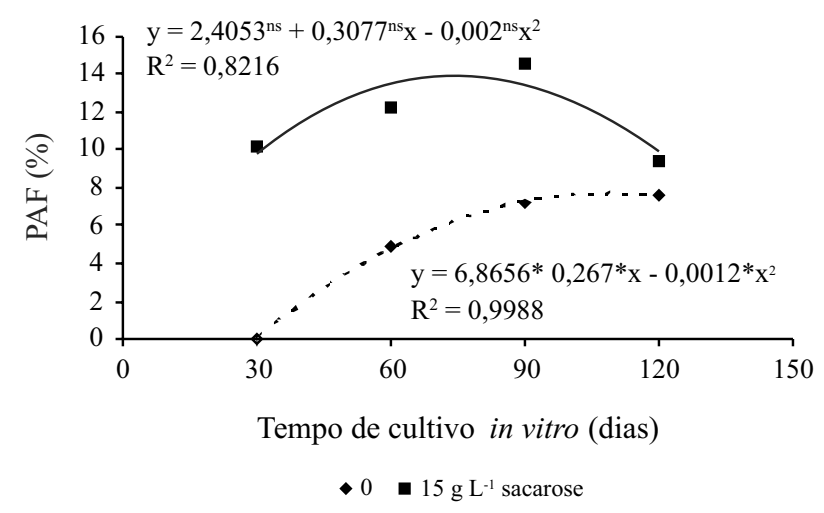

Figura 5 - Porcentagem de abscisão foliar (PAF) em função do tempo de cultivo in vitro e da concentração de sacarose

A abscisão foliar na concentração de $10 \mathrm{~g} \mathrm{~L}^{-1} \mathrm{de}$ sorbitol foi linear com coeficiente angular da reta de 0,0041 , mantendo-se quase constante (FIG. 6). Um comportamento quadrático foi obtido para $20 \mathrm{e} 40 \mathrm{~g} \mathrm{~L}^{-1}$ de sorbitol. O valor máximo da abscisão foliar para $40 \mathrm{~g} \mathrm{~L}^{-1}$ de sorbitol, por meio da derivada da equação, foi de $14,26 \%$ aos 86 dias de tempo de cultivo, ocorrendo a partir daí a redução da perda de folhas.

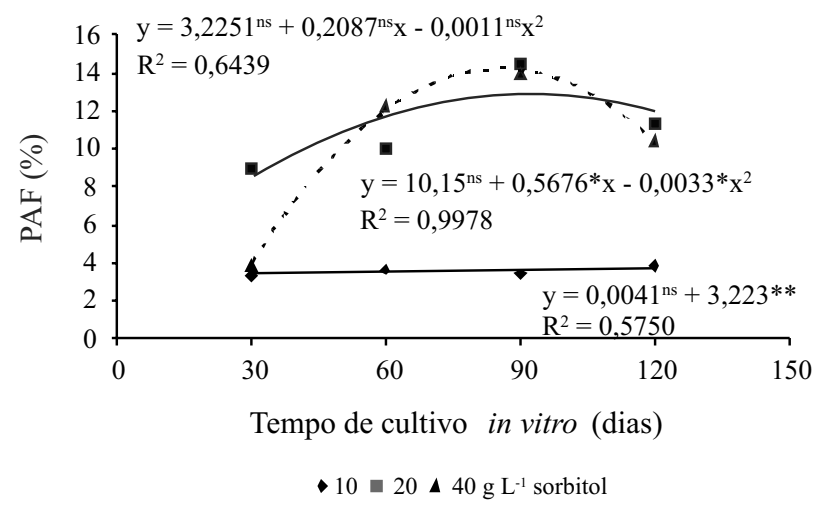

Figura 6 - Porcentagem de abscisão foliar (PAF) em função do tempo de cultivo in vitro e da concentração de sorbitol

Autores têm relatado que algumas substâncias apresentam a capacidade de inibir a ação do etileno 
in vitro e interferirem no processo de abscisão foliar (NEPOMUCENO et al., 2007; RADEMACHER, 2000). Segundo Rademacher (2000), os compostos que atuam inibindo o crescimento vegetal induzem aumento no conteúdo de citocininas, e os níveis de etileno são diminuídos, tendo como conseqüência um retardo na senescência. A redução da abscisão foliar em altas concentrações de manitol foi observada por Sá et al. (2011) em microestacas de mangabeira, embora tenha sido evidenciado seu efeito nocivo ao explante.

A manutenção da viabilidade de plantas de canade-açúcar (Saccharum officinarum L.) em crescimento lento por um ano foi possível quando se utilizou apenas $20 \mathrm{~g} \mathrm{~L}^{-1}$ de sacarose, resultando em maior viabilidade dos explantes do que na presença de sacarose combinada com manitol ou sorbitol (LEMOS et al., 2002). Segundo os autores esse fato pode ser explicado devido à canade-açúcar não possuir mecanismos necessários para metabolizar os açúcares alcoóis. Resultados semelhantes foram obtidos por Sarwar e Siddiqui (2004) que obtiveram $100 \%$ de sobrevivência de culturas de cana-de-açúcar mantidas por 105 dias na presença de 1 e $3 \%$ de manitol.

\section{Retomada do crescimento de explantes provenientes de meio de conservação com sorbitol e sacarose}

Houve efeito significativo da sacarose e do sorbitol na retomada do crescimento dos explantes até os 60 dias. Explantes mantidos na ausência de sacarose na fase de conservação apresentaram maior viabilidade com menor secamento das brotações e morte de folhas (TAB. 2).

Tabela 2 - Viabilidade de brotações de mangabeira na retomada do crescimento após a conservação in vitro em diferentes concentrações de sacarose

\begin{tabular}{cc}
\hline Sacarose $\left(\mathrm{g} \mathrm{L}^{-1}\right)$ & Viabilidade \\
\hline 0 & $2,96 \mathrm{a}$ \\
15 & $1,99 \mathrm{~b}$ \\
\hline
\end{tabular}

Médias seguidas pela mesma letra minúscula nas colunas não diferem estatisticamente entre si pelo teste de Tukey a 5\% de significância

Houve efeito significativo da interação entre sorbitol e tempo de cultivo in vitro no crescimento dos explantes. Em baixa concentração de sorbitol $\left(10 \mathrm{~g} \mathrm{~L}^{-1}\right)$, os explantes apresentaram maior viabilidade (TAB. 3 ) aos 0 ; 30 e 60 dias de cultivo in vitro. Com o aumento do tempo de cultivo in vitro, explantes mantidos em meio com $40 \mathrm{~g}$ $\mathrm{L}^{-1}$ de sorbitol apresentaram crescimento comprometido, com aumento do secamento das brotações e morte das folhas. Esse resultado pode ser explicado pelo efeito deletério do sorbitol observado na fase de conservação.

Tabela 3 - Viabilidade de brotações de mangabeira na retomada do crescimento após a de conservação in vitro em diferentes concentrações de sorbitol

\begin{tabular}{clcc}
\hline \multirow{2}{*}{ Sorbitol $\left(\mathrm{g} \mathrm{L}^{-1}\right)$} & \multicolumn{3}{c}{ Tempo de cultivo in vitro (dias) } \\
\cline { 2 - 4 } & \multicolumn{1}{c}{0} & 30 & 60 \\
\hline 10 & $3,17 \mathrm{aA}$ & $3,07 \mathrm{aA}$ & $2,85 \mathrm{aA}$ \\
20 & $2,87 \mathrm{abA}$ & $2,57 \mathrm{bA}$ & $2,17 \mathrm{bB}$ \\
40 & $2,65 \mathrm{bA}$ & $1,52 \mathrm{cB}$ & $1,37 \mathrm{cB}$ \\
\hline
\end{tabular}

Médias seguidas pela mesma letra maiúscula nas linhas e minúscula nas colunas não diferem estatisticamente entre si pelo teste de Tukey a 5\% de significância

Os explantes mantidos na presença de $10 \mathrm{mg} \mathrm{L}^{-1}$ de sorbitol na fase de conservação apresentaram maior viabilidade aos 30 e 60 dias (3,07 e 2,85, respectivamente) na retomada do crescimento. A presença de $40 \mathrm{mg} \mathrm{L}^{-1} \mathrm{de}$ sorbitol induziu menor viabilidade dos explantes.

\section{Conclusões}

1. A conservação in vitro de segmentos nodais de mangabeira na ausência de sacarose e na presença de 10 ou $20 \mathrm{~g} \mathrm{~L}^{-1}$ de sorbitol é viável sob condições de crescimento lento por 120 dias;

2. Explantes mantidos na ausência de sacarose ou na presença de $10 \mathrm{~g} \mathrm{~L}^{-1}$ de sorbitol na fase de conservação apresentam maior viabilidade na retomada do crescimento até os 60 dias de cultivo.

\section{Agradecimentos}

À Embrapa Tabuleiros Costeiros, à Fundação de Apoio à Pesquisa, à Inovação Tecnológica do Estado de Sergipe-FAPITEC/SE e ao Conselho Nacional de Desenvolvimento Científico e TecnológicoCNPq (Processos n. 562728/2008-2, 474191/2007-9, $563363 / 2010-0)$, pelo aporte de recursos financeiros e concessão de bolsa.

\section{Referências}

AMARAL, L. Conservação e propagação in vitro de três cultivares híbridas de Amarílis. 2005. 119f. Dissertação 
(Mestrado em Melhoramento Genético) - Instituto Agronômico de Campinas, Campinas. 2005.

DIVAKARAN, M. et al. Conservation of Vanilla species, in vitro. Scientia Horticulturae, v. 110, n. 02, p. 175-180, 2006.

FARIA, G. A. et al. Efeito da sacarose e do sorbitol na conservação in vitro de Plassiflora giberti N. E. Brown. Revista Brasileira de Fruticultura, v. 28, n. 02, p. 267-270, 2006.

FERREIRA, E. G. et al. Frutíferas. In: SAMPAIO, E. V. S. B., et al. Espécies da flora nordestina de importância econômica potencial. Recife: Associação Plantas do Nordeste, 2005, , p. 49-100.

HAO Y-J; DENG X-X. Genetically stable regeneration of apple plants from slow growth. Plant Cell Tissue Organ Culture, v. 72, n. 03, p. 253-260, 2003.

ISLAM, T. Md. et al. In vitro conservation of four mint (Mentha spp.) accessions. Plant Tissue Culture, v. 13, n. 01, p. 37-46, 2003.

KOVALCHUK, I. et al. Medium, container and genotype all influence in vitro cold storage of apple germplasm. Plant Cell Tissue Organ Culture, v. 96, n. 02, p. 127-136, 2009.

LÉDO, A. S. et al. Efeito da sacarose e do manitol na conservação in vitro por crescimento lento de coqueiro anão. Magistra, Cruz das Almas-BA, v. 19, n. 04, p. 346-351, 2007.

LEMOS, E. E. P. et al. Conservação in vitro de germoplasma de cana-de-açúcar. Pesquisa Agropecuária Brasileira, v. 37, n. 10, p. 1359-1364, 2002.

MURASHIGE, T.; SKOOG, F. A revised medium for rapid growth and bioassays with tobacco tissue cultures. Physiologia Plantarum, v. 15, n 43, p. 473-497, 1962.

NAIRAN, N. et al.Tecnologia do processamento do fruto. In: SILVA JUNIOR, J.; LÉDO, A. da S. A cultura da mangaba. Aracaju: Embrapa Tabuleiros Costeiros, 2006. Cap. 17, p. 222-232.
NEPOMUCENO, C. F. et al. Controle da abscisão foliar e morfogênese in vitro em culturas de Anadenanthera colubrina (Vell.) Brenan var. cebil (Griseb) Altschuh. Revista Árvore, v. 31, n. 05, p. 967-975, 2007.

RADEMACHER, W. Growth retardants: effects on gibberellin biosynthesis and other metabolic pathways. Annual Review of Plant Physiology and Plant Molecular Biology, v. 51, p. 501-531, 2000.

RENAU-MORATA, B.; ARRILLAGA, I.; SEGURA, J. In vitro storage of cedar shoot cultures under minimal growth conditions. Plant Cell Reports, v. 25, n. 07, p. 636-642, 2006.

SÁ, A. J. ; LEDO, A. da S.; LEDO. C. A. da. Conservação in vitro de microestacas de mangabeira (Hancornia speciosa Gomes). Ciência Rural, Santa Maria, v. 41, n. 01, p. 57-62, 2011.

SARWAR, M.; SIDDIQUI, S. U. In vitro conservation of sugarcane (Saccharum officinarum L.) germplasm. Pakistan Journal of Botany, v. 36, n. 03, p. 549-556, 2004.

SHIBLI, R. A. et al. In vitro conservation and cryopreservation of plant genetic resources: A review. World Journal of Agricultural Sciences, v. 02, n. 04, p. 372-382, 2006.

SHIBLI, R. A. et al. Slow growth in vitro conservation of bitter almond (Amygdalus communis L.). Advances in Horticultural Science, v. 13, n. 02 , p. 133-134, 1999.

TAHTAMOUNI et al. Growth responses and physiological disorders in wild pear (Pyrus syriaca Boiss) during slow-growth in vitro preservation on osmostressing media. Plant Tissue Culture, v. 11, n. 01, p. 15-23, 2001.

WITHERS, L. A.; WILLIAMS, J. T. Conservação in vitro de recursos genéticos de plantas. In: TORRES, A. C.; CALDAS, L. S.; BUSO, J. A. Cultura de tecidos e transformação genética de plantas. Brasília: Embrapa-SPI, 1998. Cap. 11, p. 297-330. 